\title{
PENGARUH PENAMBAHAN ALKANOLAMIDA TURUNAN MINYAK KELAPA SAWIT TERHADAP SIFAT-SIFAT UJI TARIK VULKANISAT KARET ALAM BERPENGISI SILIKA
}

\author{
Darwis Syarifuddin Hutapea, Harry Laksana Tampubolon, Indra Surya \\ Departemen Teknik Kimia, Fakultas Teknik, Universitas Sumatera Utara, \\ Jl. Almamater Kampus USU Medan 20155, Indonesia \\ Email: darwis.htpea@gmail.com
}

\begin{abstract}
Abstrak
Dengan menggunakan system vulkanisasi sulfur terakselarasi semi effisien, penelitian mengenai penggunaan alkanolamida sebagai bahan penyerasi pada campuran karet alam berpengisi silika telah dilakukan. Alkanolamida dibuat dengan direaksikannya rbdps dengan dietanolamin..Penambahan alkanolamida kedalam kompon-kompon karet alam berpengisi silika menghasilkan kompon-kompon karet alam berpengisi dimana terjadi peningkatan kekuatan tarik, modulus dan ikat silang hingga penambahan 5,0 bsk. Penambahan yang lebih banyak dari 5 bsk menyebabkan kekuatan tarik, modulus dan ikat silang menurun.
\end{abstract}

Kata kunci : Alkanolamida, Kekuatan Tarik, Ikat Silang, Vulkanisat Karet Alam.

\begin{abstract}
By using semi-efficient sulfur accelerated vulcanization sistem, an investigation about function of the alkanolamide as additive material on silica filled natural rubber was carried out. Alkanolamide was made by reacted between refined bleaching deodorized palm stearin with diethanolamine. Alkanolamide was added to the natural rubber compound silica filled, which is resulted vulcanizate natural rubber filled compound and occurring increasing of tensile strength, modulusand crosslinkdensity up to 5 phr. If was added more 5 phr, so reduction of the tensile strength modulus and crosslink density.
\end{abstract}

Keywords : Alkanolamide,Tensile Strength, Crosslink Density, Natural Rubber Vulcanizate

\section{Pendahuluan}

Umumnya sifat-sifat dari karet diperkuat silika adalah kurang baik jika dibandingkan dengan karet diperkuat hitam karbon, walaupun kedua pengisi tersebut mempunyai ukuran yang sama, [4]. Hal ini disebabkan oleh gugus silanol dari silika yang tidak serasi dengan karet hidrokarbon seperti karet alam, sehingga interaksi diantara mereka menjadi lemah. Sebaliknya, partikel-partikel silika cenderung untuk berinteraksi sesamanya, dan membentuk partikel dengan ukuran yang lebih besar. Selama interaksi silika - karet alam adalah lebih lemah dari interaksi silika - silika, maka yang akan terjadi adalah pembentukan silika yang besar, penyebaran (dispersi) partikel silika didalam phasa karet yang tidak merata, dan ini berakibat kepada efek penguatan dari silika menjadi rendah. Berdasarkan hal tersebut diatas peneliti tertarik untuk meningkatkan reaktivitas dari pengisi penguat silika terhadap karet alam, yaitu dengan penggunaan alkanolamida yang akan bertindak sebagai bahan additif yang membantu untuk meningkatkan interaksi silika dengan karet alam. Bahan tersebut adalah senyawa amida tersier, yang diperoleh melalui proses sintesa amidasi, yaitu dengan mereaksikan asam-asam lemak yang berasal dari minyak kelapa sawit dengan dietanolamina $\mathrm{NH}\left(\mathrm{CH}_{2} \mathrm{CH}_{2} \mathrm{OH}\right)_{2}$ dengan menggunakan katalis $\mathrm{CH}_{3} \mathrm{ONa}$. Molekul-molekul amida asam lemak tersebut memiliki sifat gabungan yang unik, karena rantai hidrokarbonnya yang panjang bersifat non polar sedangkan gugus aminanya bersifat sangat polar. Dengan metode ini diharapkan silika dapat dipakai sebagai pengisi penguat alternatif dengan efisiensi penguatan yang lebih baik lagi. Untuk meningkatkan efek penguatan dari silika terhadap karet alam dengan cara mengurangi kepolarannya, yaitu dengan menambahkan alkanolamida kedalam kompon karet alam berpengisi silika. Disebabkan oleh sifat kimia permukaan dari pengisi silika yang polar, maka ini merupakan kelemahan bagi silika jika digunakan sebagai pengisi penguat alternatif bagi karet alam. Maka kepolaran pengisi tersebut harus dikurangi yaitu dengan menambahkan bahan alkanolamida kedalam kompon karet alam berpengisisilika. 
Teori

Vulkanisasi adalah reaksi sambung silang (crosslinking) molekul-molekul karet oleh sulfur (belerang), sehingga dihasilkan suatu vulkanisat karet yang elastis dan kuat, [6]. Reaksi ini merubah karet yang bersifat plastis (lembut) dan lemah menjadi karet yang elastis, keras dan kuat. Vulkanisat karet tidak lagi bersifat lengket (tacky), tidak melarut tetapi hanya mengembang didalam pelarut organik tertentu, [1]. Penambahan pengisi-pengisi penguat untuk tujuan penguatan karet (rubber reinforcement) dilakukan pada saat pencampuran. Penguatan (reinforcement) disebabkan oleh daya interaksi antara karet dengan pengisi penguat. Daya ini berupa daya Van der Waals yang lemah sampai kepada ikatan-ikatan kimia yang kuat. Semakin kuat daya interaksi antara karet dengan pengisi penguat maka semakin tinggi pula derajad penguatan (degree of reinforcement) yang dihasilkan oleh pengisi penguat tersebut. Peningkatan daya interaksi antara karet dengan pengisi penguat dipengaruhi oleh faktor-faktor tertentu seperti jenis dan ukuran partikel pengisi penguat, sifat-sifat kimia dan fisika dari karet dan pengisi penguat, dan sifat geometri (porositas dan struktur) dari pengisi penguat.

\section{Metodologi Penelitian}

Penelitian dilaksanakan di Laboratorium Kimia Organik Departemen Kimia F-MIPA
USU dan Laboratorium PT Industri Karet Deli, Medan.

Bahan yang digunakan untuk membuat alkanolamida yaitu Dietanolamin, RBDPS(Rifinery Bleaching Deodorant Product Stearin), natrium metoksida, metanol, dietil eter, natrium sulfat anhydrous, natrium klorida jenuh. Sementara itu untuk melakukan uji tarik bahan yang digunakan yaitu alkanolamida, karet alam, $\mathrm{ZnO}$, asam stearat,MBTS(Benzothiazolildisulfide),IPPD (N-Isopropil-N'-phenil-phenilena amnia),sulfur,dan silika.

Rbdps ditimbang sebanyak 91,6 gram kemudian dimasukkan kedalam $1 \mathrm{~L}$ labu leher tiga lalu ditambahkan dietanolamin sebanyak 42,16 gram, dirangkai alat refluks, dihidupkan hotplate dibiarkan rbdps dan dietanolamin bercampur setelah bercampur ditambahkan campuran methanol dan natrium metoksida $(40$ $\mathrm{ml}: 10$ gram) lalu dipanaskan pada suhu 70$80{ }^{\circ} \mathrm{C}$ selama 5 jam. Setelah selesai dibiarkan beberapa menit sampai suhu kamar, selanjutnya diekstrasi dengan dietil eter sebanyak 200 gram, dicuci dengan $\mathrm{NaCl} 50$ $\mathrm{ml}$ sebanyak 3 kali. Hasilnya akan didapai 2 lapisan. Lapisan atas adalah alkanolamida dan lapisan bawah natrium metoksida. Lapisan bawah dibuang dan lapisan atas diambil ditambahkan natrium sulfat anhydrous dibiarkan selama 1 hari. Kemudian disaring dengan kertas saring, filtratnya diuapkan dengan alat vaporator sehingga didapat alkanolamida dalam bentuk semi padat (gel).

Tabel 1. Sistem vulkanisasi sulfur terakselerasi semi-effisien

\begin{tabular}{|c|l|c|c|c|c|c|c|}
\hline $\begin{array}{c}\mathrm{N} \\
\mathrm{o}\end{array}$ & Nama Bahan & $\begin{array}{c}\text { Kompon } \\
\mathrm{A}(\mathrm{bsk}) *\end{array}$ & $\begin{array}{c}\text { Kompon } \\
\mathrm{B}(\mathrm{bsk})^{*}\end{array}$ & $\begin{array}{c}\text { Kompon } \\
\mathrm{C}(\mathrm{bsk})^{*}\end{array}$ & $\begin{array}{c}\text { Kompon } \\
\mathrm{D}(\mathrm{bsk})^{*}\end{array}$ & $\begin{array}{c}\text { Kompon } \\
\mathrm{E}(\mathrm{bsk})^{*}\end{array}$ & $\begin{array}{c}\text { Kompon } \\
\mathrm{F}(\mathrm{bsk})^{*}\end{array}$ \\
\hline 1 & Karet alam & 100,0 & 100,0 & 100,0 & 100,0 & 100,0 & 100,0 \\
\hline 2 & ZnO & 5,0 & 5,0 & 5,0 & 5,0 & 5,0 & 5,0 \\
\hline 3 & Asam stearat & 3,0 & 3,0 & 3,0 & 3,0 & 3,0 & 3,0 \\
\hline 4 & MBTS & 2,0 & 2,0 & 2,0 & 2,0 & 2,0 & 2,0 \\
\hline 5 & IPPD & 2,0 & 2,0 & 2,0 & 2,0 & 2,0 & 2,0 \\
\hline 6 & Sulfur & 2,0 & 2,0 & 2,0 & 2,0 & 2,0 & 2,0 \\
\hline 7 & Silika & 30 & 30 & 30 & 30 & 30 & 30 \\
\hline 8 & Alkanolamida & 0 & 1 & 3 & 5 & 7 & 9 \\
\hline
\end{tabular}

* bagian per seratus karet alam (bsk) 
Pencampuran karet alam dan bahan-bahan lain dilakukan pada two-roll mill. Karet alam, alkanolamida,silika dan bahan-bahan lainnya dicampur sampai mencapai keadaan homogen pada suhu yang dijaga konstan pada \pm 65 $75{ }^{0} \mathrm{C}$ selama \pm 25 menit untuk satu siklus pencampuran. Sampel senyawa karet yang berupa lembaran disimpan dengan kondisi \pm 21-25 ${ }^{\circ} \mathrm{C}$ selama \pm 24 jam. Didalam suatu freezer tertutup sebelum dilakukan pengujian terhadap sifat-sifat uji tarik. Penyediaan dan pengujian sampel. Sampel-sampel berbentuk dumbel dipotong dari lembaran vulkanisat karet pada ketebalan $2 \mathrm{~mm}$ dengan pisau pemotong yang juga berbentuk dumblle. Panjang dan lebar sampel $31-35 \mathrm{~mm}$ dan $6,2-6,4 \mathrm{~mm}$. Sampel ini diuji sifat uji tariknya.Prosedur sifat-sifat uji tarik dilakukan dengan melakukan standarisasi ASTM D 412-92 Test method A yaitu dengan menggunakan Tensometer Monsanto (Model T10) yang beroperasi dengan kecepatan 50 $\mathrm{cm} / \mathrm{min}$. sifat-sifat uji tarik dilakukan dengan melakukan pembacaan kekuatan tarik (Tensile Strength) dan pesentasi pemanjangan pada saat putus (\% elongation at break) yang terekam dalam display dari Tensometer T10 pada akhir pada setiap pengujian.

\section{Hasil dan Pembahasan}

Adapan hasil FT-IR dari alkanolamida disajikan pada gambar berikut,

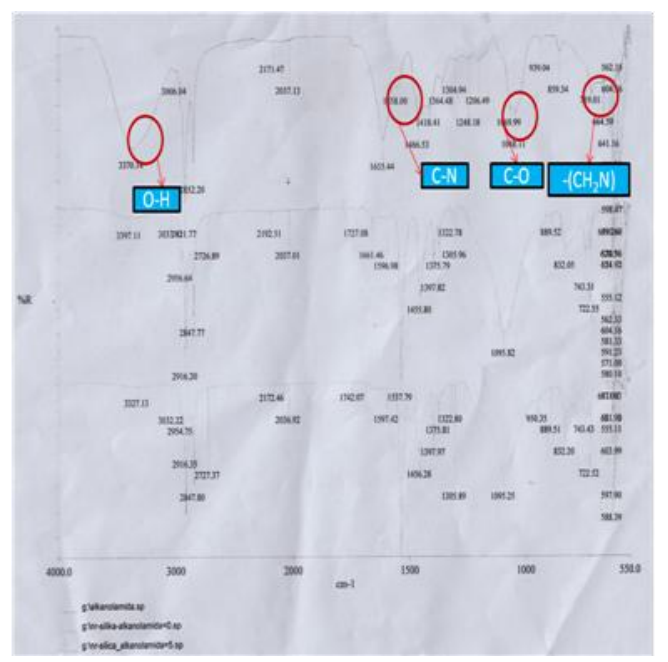

Gambar 1. FT-IR alkanolamida

Hasil dari pembuatan alkanolamida dibuktikan melalui bilangan gelombang yang terbentuk dari gugus karbonil amida yang didukung oleh munculnya pita serapan pada bilangan gelombang $\mathrm{C}-\mathrm{N}\left(1558 \mathrm{~cm}^{-1}\right)$. Pada bilangan gelombang daerah $3356 \mathrm{~cm}^{-1}$ menunjukkan vibrasi gugus $\mathrm{OH}$ yang diperkuat oleh puncak serapan pada bilangan gelombang $1069 \mathrm{~cm}^{-1}$ yang merupakan vibrasi stretching $\mathrm{C}-\mathrm{O}$ dan $\mathrm{C}-\mathrm{OH}$. Pada bilangan gelombang 717 merupakan $-\left(\mathrm{CH}_{2}\right)_{\mathrm{n}}$ yang merupakan rantai hidrokarbon alkil rantai panjang, [5].

Gambar berikut menyatakan kerapatan sambung silang,

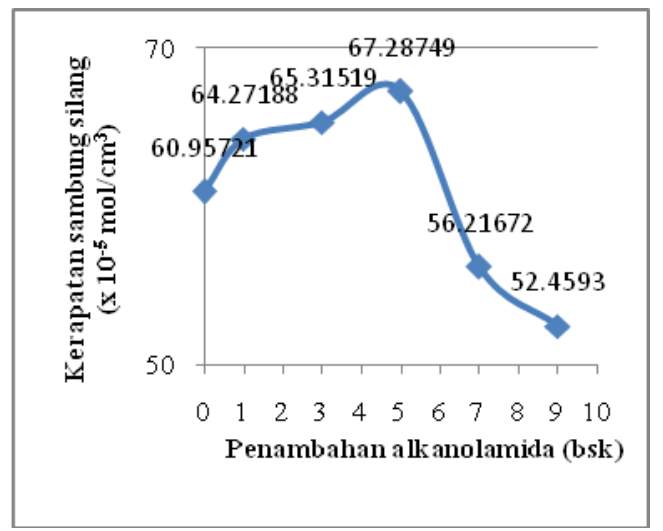

Gambar 2. Grafik Kerapatan sambung silang vulkanisat karet alam berpengisi silika dan alkanolamida.

Penambahan alkanolamida sampai kadar 5 bsk mengalami peningkatan. Hal ini dapat disebabkan, alkanolamida dapat bertindak sebagai bahan yang membantu proses atau reaksi sambung silang (curative agent), yaitu dapat membentuk sambung silang tambahan, baik sambung silang secara kimia maupun sambung silang fisikal antara silika dengan karet alam. Penambahan sambung silang ini menyebabkan peningkatan kerapatan sambung silang vulkanisat karet, [2]. Penambahan yang lebih dari 5 bsk vulkanisat mengalami penurunan karena kadar bahan tersebut bertindak sebagai pelarut (solvent) yang membuat sulfur dan bahan kuratif lainnya melarut (solute) ke dalam bahan tersebut, sehingga menyebabkan penurunan kerapatan sambung silang bagi vulkanisat karet tersebut.

Gambar ini menunjukkan modulus tensil vulkanisat karet alam berpengisi silika dan alkanolamida. 


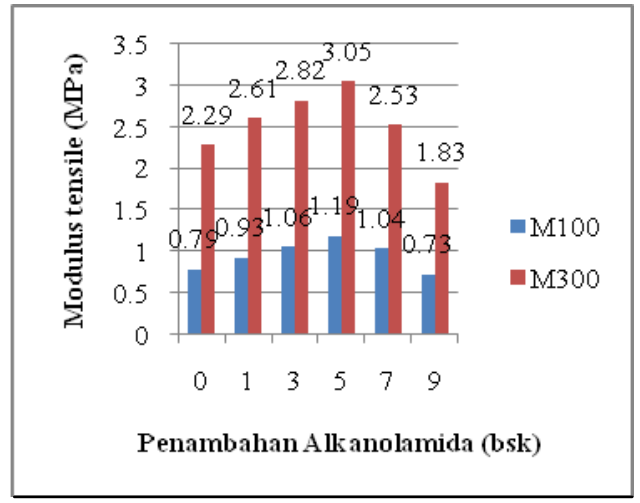

Gambar 3. Modulus tensil vulkanisat karet alam berpengisi silika dan alkanolamida.

Dari kurva diatas, terlihat bahwa penambahan alkanolamida ke dalam kompon karet alam berpengisi silika sebanyak 1,0 bsk menghasilkan vulkanisat karet alam berpengisi silika dan alkanolamida (vulkanisat 1,0) dengan modulus tensil (M100 dan M300) yang lebih tinggi. Penambahan alkanolamida ke dalam kompon karet berpengisi tersebut dengan kadar yang lebih tinggi hingga 5,0 bsk. menyebabkan M100 dan M300 dari vulkanisat karet berpengisi tersebut menjadi lebih tinggi. Peningkatan nilai modulus tensil ini menyebabkan vulkanisat karet berpengisi tersebut menjadi lebih kaku, effek kekakuan ini disebabkan oleh peningkatan kerapatan sambung silang, melalui peningkatan interaksi baik pengisi silika maupun alkanolamida dengan molekul karet alam, sehingga kerapatan sambung silang meningkat, yang menyebabkan rantai-rantai molekul karet alam susah untuk bergerak. Sehingga dapat dikatakan penambahan alkanolamida ke dalam kompon karet alam berpengisi silika sama saja dengan meningkatkan kerapatan sambung silang dari vulkanisat karet berpengisi tersebut. Penambahan alkanolamida yang lebih dari 5,0 bsk. menyebabkan nilai M100 dan M300 dari vulkanisat karet berpengisi tersebut menjadi menurun. Hal ini disebabkan jumlah/kadar yang lebih banyak dari alkanolamida tersebut membuat ianya dapat bertindak sebagai bahan yang dapat melarutkan bahan-bahan kuratif, sehingga menurunkan kerapatan sambung silang yang mungkin dibentuk. Penjelasan ini konsisten dengan effek alkanolamida terhadap kerapatan sambung silang vulkanisat karet alam berpengisi silika dan alkanolamida.
Untuk melihat seberapa kuat karet alam maka dilakukan uji kekuatan tarik yang disajikan pada gambar berikut,

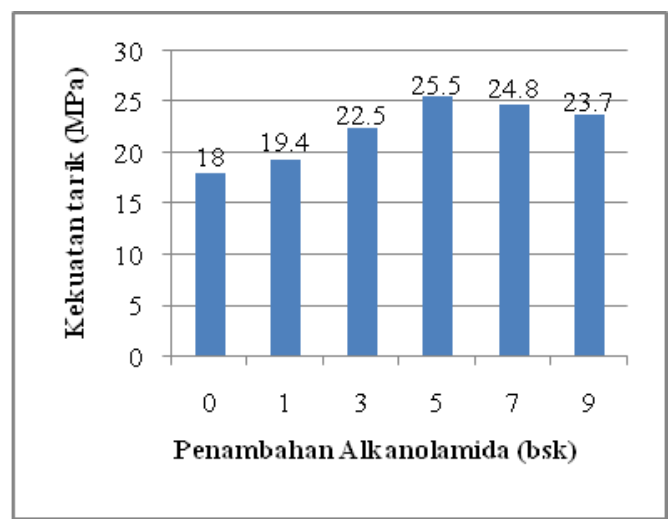

Gambar 4. Kekuatan tarik vulkanisat karet alam berpengisi silika dan alkanolamida.

Kekuatan tarik dari vulkanisat Karet Alam berpengisi silika meningkat dengan penambahan alkanolamida dari 1,0 bsk hingga 5,0 bsk. Peningkatan kekuatan ini dapat disebabkan oleh karena alkanolamida dapat bertindak sebagai bahan yang dapat meningkatkan kerapatan sambung silang dari vulkanisat karet alam berpengisi silika. Peningkatan penambahan alkanolamida lebih lanjut menyebabkan penurunan kekuatan tarik vulkanisat Karet Alam berpengisi silika tersebut, Penjelasan ini konsisten dengan effek alkanolamida terhadap kerapatan sambung silang vulkanisat karet alam berpengisi silika dan alkanolamida.

Gambar ini menunjukkan pemanjangan saat putus dari vulkanisat,

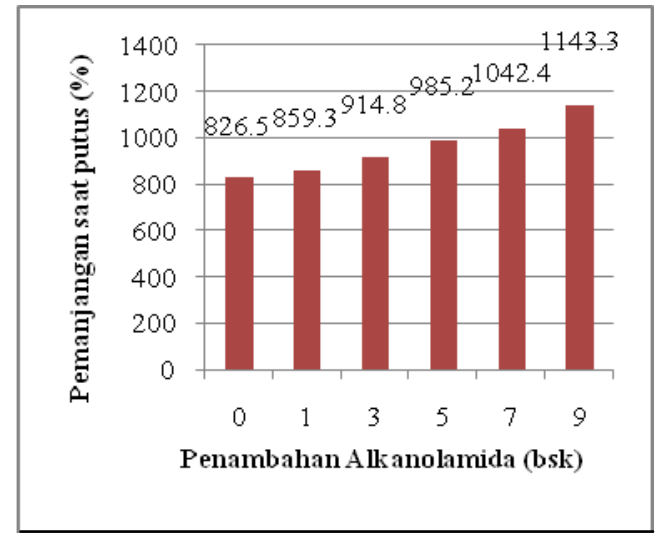

Gambar 5. Pemanjangan saat putus vulkanisat karet alam berpengisi silika dan alkanolamida. 
Pengaruh saat putus dari vulkanisat Karet Alam berpengisi silika meningkat dengan penambahan alkanolamida. Sehingga dapat dikatakan penambahan alkanolamida ke dalam kompon karet alam berpengisi silika dapat meningkatan ekstensibilitas dari vulkanist karet berpengisi tersebut. Efek dari bahan tersebut sama seperti bahan pemlastik (minyak) yang dapat meningkatkan pemanjangan saat putus dari vulkanisatvulkanisat karet. Bagaimana pun alkanolamida adalah turunan daripada minyak sawit, sehingga bahan tersebut dapat juga bertindak sebagai bahan pemlastis (plastizicer).

\section{Kesimpulan}

Penambahkan alkanolamida kedalam kompon karet alam berpengisi silika, hingga 5 bsk menyebabkan kenaikan kekuatan tarik, modulus tensile dan ikat silang dari vulkanisat karet alam berpengisi silika. Penambahan yang lebih besar dari 5 bsk menyebabkan kekuatan tarik modulus tensile dan ikat silang dari vulkanisat berpengisi silika menjadi menurun. Kemungkinan hal ini disebabkan alkanolamida telah bersifat sebagai bahan pelarut yang dapat melarutkan bahan-bahan puratif.

Ucapan Terimakasih
Pada kesempatan ini $\begin{array}{r}\text { Peneliti } \\ \text { mengucapkan } \\ \text { Laboratorium Kimia Organik }\end{array}$

dan PT Industri Karet Deli yang telah membantu didalam penyediaan tempat penelitian didalam membuat alkanolamida dan pengujian terhadap sifat-sifat uji tarik dari vulkanisat.

\section{Daftar Pustaka}

[1] M. Akiba \& A.S.Hashim, Vulcanization and crosslinking in elastomers, Prog. Polym. Sci., 1997, p. 475 521.

[2] G. Kraus, Interactions of elastromers and reinforcing fillers, Rubber Chem,Technol, 1965, p.10701114.

[3] K. E. Polmanteer \& Lentz, C.W, Reinforcement studies-effect of silica structure on properties and crosslink density, Rubber Chem. Technol.48, 1975,p.795-809.

[4] P. E. Pinter \& Mc. Gill, C.R,Comparing rubber fillers in an energy concious economy, Rubber World International. 1978, p.117.

[5] M. R, Silverstein, Spectrometric Identification of Organic Compounds. Fourth edition. John Wiley \& Son, New York,1997, p.166-170.

[6] Indra Surya, Pengaruh penambahan Bis (3trietoksisililpropil) tetrasulfida pada pengukuhan silika terhadap sifatsifat uji tarik karet alam, Jurnal Teknologi Proses, Vol. 1 No, 2002 